\title{
Management of Aerosol during Noninvasive Ventilation for Patients with Sleep-Disordered Breathing: Important Messages during the COVID-19 Pandemic
}

\author{
Abdul Rouf Pirzada ${ }^{1}$ Salih A. Aleissi ${ }^{1} \cdot$ Aljohara S. Almeneessier $^{1,2}\left[\right.$ - Ahmed Salem BaHammam ${ }^{1}$ (1)
}

Received: 21 May 2020 / Revised: 21 May 2020 / Accepted: 1 June 2020 / Published online: 17 June 2020

(c) Springer Nature Singapore Pte Ltd. 2020

\begin{abstract}
With the advent of COVID-19 infection and its rapid spread, preventive strategies are being developed worldwide, besides following the universal infection control guidelines. Prevention of spread through aerosol generation is one of the essential strategies in this regard, particularly for patients with sleep-disordered breathing at home and during hospital admission. Aerosols are produced, at home and in health care facilities, by natural processes and aerosol-generating procedures. To address this impinging problem, aerosol-generating procedures, like non-invasive ventilation (NIV), are to be handled meticulously, which might warrant isolation and sometimes device/interface modifications.
\end{abstract}

Keywords SARS-co-V-2 $\cdot$ Obstructive sleep apnea $\cdot$ CPAP $\cdot$ Coronavirus $\cdot$ Home ventilation

\section{Introduction}

First reported in Wuhan, China, in December 2019, with subsequent global spread, "coronavirus disease 2019" (COVID 19) infection was later declared as a pandemic by World Health Organization (WHO). The sheer number of persons infected, along with the rapid worldwide dispersion, it has threatened the health care systems all over the world. COVID-19 is mainly transmitted through respiratory droplets: close unprotected contact, and intense aerosolsgenerating procedures [1]. Thus, the community spread from person to person, and through fomites, the spread of infection in healthcare workers is a more formidable threat. The spread of infection among healthcare workers has more implications since it jeopardizes the already reeling system [2]. As the spread of infection in COVID 19 is by droplets,

Aljohara S. Almeneessier

aljoharas@yahoo.com

$\triangle$ Ahmed Salem BaHammam

ashammam2@gmail.com

1 Department of Medicine, College of Medicine, The University Sleep Disorders Center, King Saud University, Riyadh, Saudi Arabia

2 Family Medicine, College of Medicine, King Saud University, Riyadh, Saudi Arabia which happens during close contact or through fomites; thus, the management of droplet dispersion forms the soul of the prevention strategy [3]. Droplets or large aerosols are usually of the size of more than $20 \mu \mathrm{m}$. These are produced either during natural processes like coughing, sneezing or during aerosol-generating procedures, like non-invasive ventilation (NIV) [2]. It has been shown that masks, particularly common medical/surgical masks can prevent the natural process of droplet spread though it is "easier said than done" and the N95 masks are to be reserved for high-risk encounters; however, aerosol management during aerosol-generating procedures is still a challenge [4]. This review aims to formulate guidelines and advisories for aerosol management during NIV [particularly for patients with sleep-disordered breathing (SDB)] and related procedures after critically reviewing the scientific literature available so far; nevertheless, these guidelines and advisories are dynamic due to the evolving nature of the pandemic.

\section{Aerosols}

Aerosols are particles suspended in the air that can contain a variety of pathogens, including viruses, and their classification is debatable. Arbitrarily, aerosols are categorized as small droplets (which are usually called aerosols exclusively) and large droplets, with small droplets having the 
potential to desiccate and form droplet nuclei that travel long distances, while large droplets do not evaporate before settling on surfaces [5]. This aerosol classification has clinical relevance in relation to their dispersal properties and patterns, but it is also important to classify aerosols according to where they deposit in the respiratory tract, upper or lower, because it has a bearing on pathogenesis [5, 6]. Most often, 5 microns in diameter is taken as a cutoff for small droplets, while another possible cutoff between aerosol types is 20 microns, since aerosols less than or equal to 20 microns in diameter can desiccate to form droplet nuclei, and aerosols more 20 microns do not deposit substantially in the lower respiratory tract [5].

In the case of COVID 19, it has been experimentally postulated that the epidemiological characteristics of this virus probably arise from other plausible factors like high viral load in the upper respiratory tract and the potential for infected persons to shed and transmit the virus while asymptomatic $[4,5,7]$. Besides, aerosol and fomite transmission of COVID 19 is highly possible, since the virus can remain viable and infectious in aerosols for hours and on surfaces up to days (depending on the inoculum shed) $[8,9]$.

Aerosol generation can occur during natural processes like coughing, sneezing, or expectorating; however, current evidence suggests that, while it is possible that coronaviruses can survive in the aerosol from within fluid particles, under certain conditions, this is not the primary mechanism for transmission in the community. However, the natural processes are presumed to be a potential transmission mechanism in health care workers, besides therapeutic or diagnostic aerosol-generating procedures. The procedures that are believed to have a potential to generate aerosols and droplets as a source of respiratory pathogens include positive pressure ventilation (bilevel positive airway pressure (BPAP) and continuous positive airway pressure (CPAP)), endotracheal intubation, airway suction, high-frequency oscillatory ventilation, tracheostomy, chest physiotherapy, nebulizer treatment, sputum induction, and bronchoscopy [5-7]. In experimental studies, this phenomenon of aerosol generation and dispersion has been studied. However, those experimental studies had some practical short-comings because they used smoke to simulate aerosol, and experiments were conducted in the absence of negative pressure [3]. During NIV, studies demonstrated that the dispersion had been grossly variable depending upon multiple factors like the interface used, pressure level, and the device used [3].

Respiratory procedures are known to stimulate coughing and promote the generation of aerosols; however, their risk of transmission of infection is not quantified. Thus, these procedures are to be handled meticulously to minimize the spread among health care workers and at times in the household [10-12].
This short review aims to formulate guidelines and advisories for home and hospital use of NIV. Since the aerosolgenerating procedures take place at home and in the hospital, we will divide this article into two sections, at home and in the hospital.

\section{At home}

Aerosol generating procedures that take place at home are home NIV systems, either CPAP or a BPAP, home oxygen therapy, and sometimes home diagnostics like "home sleep apnea testing" systems. NIV, BPAP, and CPAP are currently listed by the $\mathrm{WHO}$ as a high-risk aerosol-generating procedure. NIV accounts for high-dose viral transmission risk to family and carers during the treatment of chronic respiratory diseases, especially obstructive sleep apnea [13-17]. The viral load is comparable in nasal and throat swabs of symptomatic and asymptomatic patients with COVID-19 [17], suggesting that NIV-induced aerosolization of nasopharyngeal secretions from asymptomatic patients may pose similar risks for high-dose viral transmission in households. Aerosolised severe acute respiratory syndrome coronavirus 2 (SARS-CoV-2) has a half-life of $1.1 \mathrm{~h}$ in the air, and therefore, a period of prolonged isolation may be required following NIV usage $[3,8,9]$. However, patients with sleepdisordered breathing need to use their positive airway pressure (PAP) devices during this pandemic that may last for months to come, besides CPAP use can have a bearing on overall mortality and morbidity in these patients if infected with SARS-CoV-2 [18-20].

Based on the literature review and personal experience $[16,17,21-23]$, the following is suggested:

- Universal isolation for NIV at home is impractical; hence it has to be individualized.

- Temporary cessation is a plausible option, taking into consideration the risks of withholding NIV in patients with hypercapnia; however, this needs to be discussed with the treating physician. In patients with whom NIV therapy cannot be temporarily stopped, such as patients with severe obesity hypoventilation, complete home isolation is preferred to minimize the risk of aerosol spread among the household.

- Other plausible options are modifications in the device and interface of NIV to reduce the risk of aerosol dispersion (will be discussed down).

- Following routine hygiene advisories are highly recommended: changing machine filters routinely, cleaning surfaces, cleaning masks and tubing with hand-hot soap water (washing-up liquid), and washing hands regularly.

- For home oxygen therapy, isolation is a must to prevent the viral dispersion if there is suspicion or confirmation 
of COVID-19 infection as viral load and dispersion inhome oxygen systems, though not quantified, is highly infective.

- Portable home sleep studies and auto-adjusting PAP at home are recommended to be suspended, particularly in endemic zones; however, they can be considered in emergent conditions in sporadic zones, only after ruling out any suspicion of COVID-19 infection. In such circumstances, the applications of a disposable nasal pressure transducer for sleep study and disposable or personal masks and ventilator tubing for NIV are strongly recommended [16, 17, 21-23].

\section{In hospital}

In the hospital, the procedures that are believed to or have a potential to generate aerosols and droplets as a source of respiratory pathogens include positive pressure ventilation (BiPAP and CPAP), endotracheal intubation, airway suction, high-frequency oscillatory ventilation, tracheostomy, chest physiotherapy, nebulizer treatment, sputum induction, and bronchoscopy $[5,8]$. It is imperative to mention that titration studies during polysomnography fall under the same category.

Hence, in countries with endemic zones, it is recommended to suspend sleep studies except in emergent conditions after examining the risk-benefit ratio with a strict precondition of pre-procedural evaluation for COVID-19 [21, 24]. Besides, it is necessary to follow the infectious disease protocol of negative pressure isolation and proper personal protective equipment (PPE), whenever indicated. Indication for infectious disease protocol is, nevertheless, ambiguous and hence has to be individually tailored [21, 23, 25].

In the regions/areas with sporadic COVID-19, sleep study and NIV can be continued, but it is recommended to have portable home sleep studies and auto-adjusting PAP at home. The applications of a disposable nasal pressure transducer for sleep study and disposable or personal masks and ventilator tubing for NIV are strongly suggested. However, it is recommended to suspend sleep studies and NIV titration trials for subjects who report to having recent travel or residential history in a high epidemic area [21], contact history with COVID-19 infected patients, contact history with febrile patients or subjects with respiratory tract symptoms from the high epidemic or cluster outbreak area, report of fever or respiratory tract symptoms, or newly emerging ground-glass opacities on a computerized chest tomography (CT) scan [21, 23, 25]. For the recovered patients with robust evidence of negative results of nucleic acid testing, sleep studies and NIV can be performed [21, 23, 25].

For in-hospital NIV, dispersion of virus is common if robust preventive measures are not applied. NIV in hospital, in a setting of suspected or confirmed case of COVID-19, warrants infectious disease protocol of isolation in negative pressure room preferably with an anteroom and attached washroom (well ventilated) and personal protective equipment for attending staff; however, it is not possible in high volume patient inflow. Even under such unavoidable conditions, PPE for the attending staff is mandatory $[3,16,17,26,27]$.

A practical approach is to work on and modify the NIV device, mostly interface and tubing to minimize the dispersion and protect the health care workers.

Setup of CPAP or NIV/Bilevel ventilators for patients with SDB is built to work with a single tube and a relatively constant intentional leak. The leak occurs in three parts: mouth leak, if a nose mask is used, leak around the mask/face contact, and leak through the intentional leak port.

Interventions to reduce leak include the use of a full-face mask (discarding nasal masks) with the optimal fit; moreover, the mask needs to be non-vented with an exhalation port in the circuit. Thus, the choice of a mask to minimize viral dispersion would be $[3,24,26,28]$ :

- First choice, a full-face non-vented mask with an expiratory viral filter. A good mask seal for face masks is important to minimize droplet dispersion and maximize effectiveness.

- Second choice, a helmet with air cushion for CPAP.

- Third choice, a helmet without air cushion for CPAP.

- Fourth choice, a standard face mask

It is important while using a mask-system to humidify the gas flow. A heat and moisture exchanger (HME)/viral filter should be fitted to all exhaust systems to reduce droplet spread. HME filters need a close watch to look for any waterlogging that warrants a change to prevent any high and unidirectional flow. It must be ensured that the ventilator mode employed supports the use of non-vented masks and exhalation ports. Likewise, the sequence of events protocol should be: to put the mask on, tie it, and then put the ventilator on; to disconnect, first put the ventilator off, and then take off the mask.

To manage intentional leak, a viral/bacterial filter can be placed in the circuit between the mask and the oxygen and exhalation ports to ensure that if the oxygen tubing becomes dislodged accidentally, the filter will stop exhaled breaths escaping via the ports (Fig. 1) [22]. This viral/bacterial filter can replace any filter at the machine end of the circuit and ideally needs to be changed every $24 \mathrm{~h}$ to prevent any resistance to flow due to the absorption of moisture, which can mimic clinical deterioration. It is important to mention that external humidification should not be used in such systems [22]. 


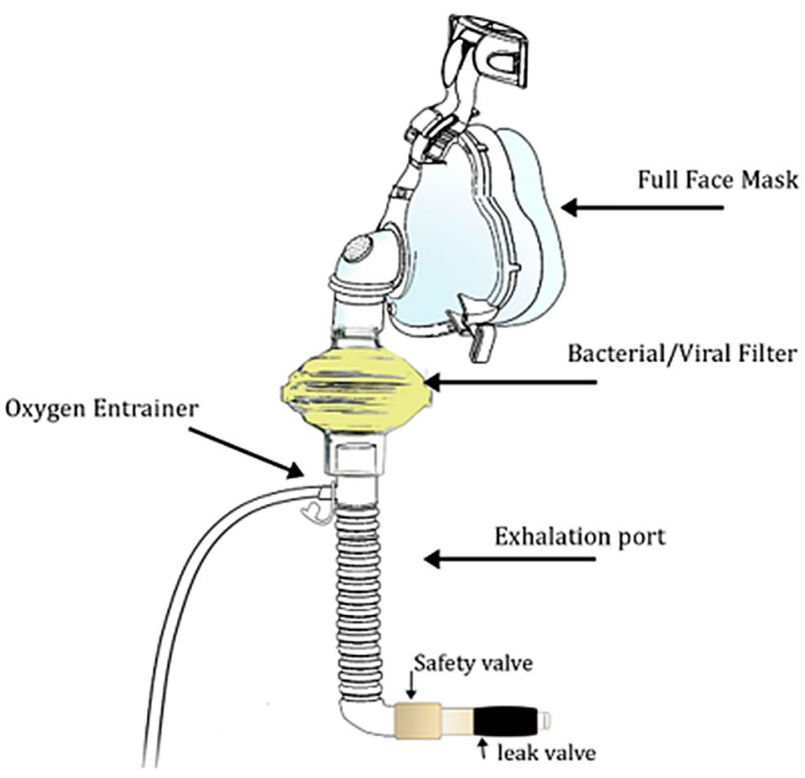

Fig. 1 A scheme of NIV setup, a non-vented mask is fitted to a bacterial filter, and then connected to a safety valve and an oxygen entrainer port in between, at the end an exhalation port with a valve

Whenever oxygen is to be used, it can be entrained into the circuit, and this should be done at the patient end of the filter Fig. 1). Once a patient is admitted to the hospital with suspicion/confirmed COVID-19 and is using home NIV systems, it is essential to ensure that the used mask is nonvented, the filter is entrained in the system, and there is no humidifier [22, 26, 29].

To act during the exigencies of patient volume and meager resources, it is suggested to follow "jury rig," which is a system tailored to circumvent the lack of a commercial bilevel circuit with an exhalation port; this can be done so by connecting a $\mathrm{T}$ - or $\mathrm{Y}$-connector to the mask, then fit a filter in the new limb; besides, introducing an exhalation port (or resistor containing leak), which can be inserted before (or after) the filter [30].

This addition of a "T" or "Y" tube piece with an "overflow" port allows filtering of all, but the unintentional face leak (which can be managed using an appropriate mask); however, it creates dead-space, which can be minimized by connecting the $\mathrm{Y}$ or $\mathrm{T}$ piece as close as feasible to the mask (Fig. 2). Merely adding a filter on the end of the "overflow" tube will dissipate much of the delivered pressure from the ventilator, unless, it is combined with a resistor. Thus, the combination of a filter and a resistor/ restrictor in the right range will correct this issue. If a resistor is not commercially available, it can be tailored using a plug with a single $3.5 \mathrm{~mm}$ (1/8 or $5 / 32$ inch) hole drilled in it or $200.8 \mathrm{~mm}$ holes drilled in a standard medication pillbox that fits the tubing; holes are punctured/ melted into the bottom with a hot paper clip or 18-gauge needle) [30]. This arrangement should provide leak flow of $12 \mathrm{l} / \mathrm{min}$ at $3 \mathrm{cmH} 20$, and $35 \mathrm{l} / \mathrm{min}$ at $25 \mathrm{~cm} \mathrm{H} 20$, providing adequate ventilation at most bilevel settings without significant $\mathrm{CO}_{2}$ rebreathing [30]. The setup would replicate the typical leak port flows of existing masks or expiratory port circuits directed to a filter (Fig. 2). Sterility of this part of the circuit is not a significant issue as the flow is unidirectional away from the patient, even when the patient is intubated [29, 30].

Other aerosol-generating ward procedures like nebulization and oxygen therapy in suspected or confirmed COVID-19 patients warrant a standard infectious disease protocol, as already mentioned. Procedures like bronchoscopy and endotracheal intubation are beyond the scope of our discussion.
Fig. 2 A schematic representation of a modified bilevel circuitry setup to minimize aerosol dispersion by adding a Y-connector, with one limb connected to the device and the other limb to a filter through a restrictor

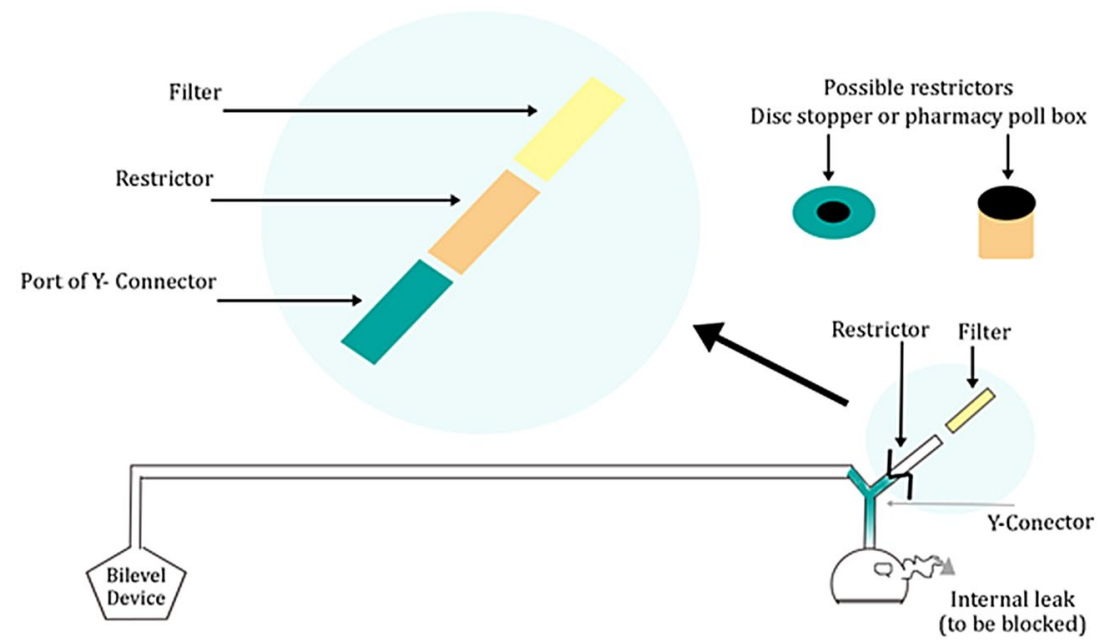




\section{Summary}

Aerosol management during NIV use can be achieved through multiple methods, besides suspending the use, whenever possible. Standard infectious disease protocols form the backbone of the preventive strategy; however, modifications in the interface and the tubing can be tailored through commercially available add-ons or using home available materials to limit the aerosol dispersion during NIV use.

Funding This work was supported by the Strategic Technologies Program of the National Plan for Sciences and Technology and Innovation in the Kingdom of Saudi Arabia (MED511-02-08). The study sponsors played no role in the study design, the collection, analysis or interpretation of data, writing the manuscript, or the decision to submit the manuscript.

\section{Compliance with ethical standards}

Conflict of interest The authors have no conflict of interest to declare.

\section{References}

1. Rothan HA, Byrareddy SN. The epidemiology and pathogenesis of coronavirus disease (COVID-19) outbreak. J Autoimmun. 2020;109:102433. https://doi.org/10.1016/j.jaut.2020.102433.

2. Brewster DJ, Chrimes N, Do TB, Fraser K, Groombridge CJ, Higgs A, Humar MJ, Leeuwenburg TJ, McGloughlin S, Newman FG, Nickson CP, Rehak A, Vokes D, Gatward JJ. Consensus statement: Safe Airway Society principles of airway management and tracheal intubation specific to the COVID-19 adult patient group. Med J Aust. 2020. https://doi.org/10.5694/mja2.50598.

3. Ferioli M, Cisternino C, Leo V, Pisani L, Palange P, Nava S. Protecting healthcare workers from SARS-CoV-2 infection: practical indications. Eur Respir Rev. 2020;29:155. https://doi. org/10.1183/16000617.0068-2020.

4. Bartoszko JJ, Farooqi MAM, Alhazzani W, Loeb M. Medical masks vs N95 respirators for preventing COVID-19 in healthcare workers: a systematic review and meta-analysis of randomized trials. Influenza Other Respir Viruses. 2020. https://doi.org/10.1111/ irv. 12745 .

5. Judson SD, Munster VJ. Nosocomial transmission of emerging viruses via aerosol-generating medical procedures. Viruses. 2019;11:10. https://doi.org/10.3390/v11100940.

6. Hui DS, Chow BK, Lo T, Tsang OTY, Ko FW, Ng SS, Gin T, Chan MTV. Exhaled air dispersion during high-flow nasal cannula therapy versus CPAP via different masks. Eur Respir J. 2019;53:4. https://doi.org/10.1183/13993003.02339-2018.

7. Thomas RJ. Particle size and pathogenicity in the respiratory tract. Virulence. 2013;4(8):847-58. https://doi.org/10.4161/viru.27172

8. van Doremalen N, Bushmaker T, Morris DH, Holbrook MG, Gamble A, Williamson BN, Tamin A, Harcourt JL, Thornburg NJ, Gerber SI, Lloyd-Smith JO, de Wit E, Munster VJ. Aerosol and surface stability of SARS-CoV-2 as compared with SARS-CoV-1. N Engl J Med. 2020;382(16):1564-7. https://doi.org/10.1056/ NEJMc2004973.
9. Zou L, Ruan F, Huang M, Liang L, Huang H, Hong Z, Yu J, Kang M, Song Y, Xia J, Guo Q, Song T, He J, Yen HL, Peiris M, Wu J. SARS-CoV-2 viral load in upper respiratory specimens of infected patients. N Engl J Med. 2020;382(12):1177-9. https ://doi.org/10.1056/NEJMc2001737.

10. Hunter JC, Nguyen D, Aden B, Al Bandar Z, Al Dhaheri W, Abu Elkheir K, Khudair A, Al Mulla M, El Saleh F, Imambaccus H, Al Kaabi N, Sheikh FA, Sasse J, Turner A, Abdel Wareth L, Weber S, Al Ameri A, Abu Amer W, Alami NN, Bunga S, Haynes LM, Hall AJ, Kallen AJ, Kuhar D, Pham H, Pringle K, Tong S, Whitaker BL, Gerber SI, Al Hosani FI. Transmission of middle east respiratory syndrome coronavirus infections in healthcare settings. Abu Dhabi Emerg Infect Dis. 2016;22(4):647-56. https://doi.org/10.3201/eid2204.151615.

11. Pshenichnaya NY, Nenadskaya SA. Probable Crimean-Congo hemorrhagic fever virus transmission occurred after aerosolgenerating medical procedures in Russia: nosocomial cluster. Int J Infect Dis. 2015;33:120-2. https://doi.org/10.1016/j. ijid.2014.12.047.

12. Davies A, Thomson G, Walker J, Bennett A. A review of the risks and disease transmission associated with aerosol generating medical procedures. J Infect Prevent. 2009;10(4):122-6. https://doi.org/10.1177/1757177409106456.

13. Arulkumaran N, Brealey D, Howell D, Singer M. Use of noninvasive ventilation for patients with COVID-19: a cause for concern? Lancet Respir Med. 2020. https://doi.org/10.1016/ S2213-2600(20)30181-8.

14. Singh A, Sterk PJ. Noninvasive ventilation and the potential risk of transmission of infection. Eur Respir J. 2008;32(3):816. https ://doi.org/10.1183/09031936.00052208.

15. Esquinas AM, Egbert Pravinkumar S, Scala R, Gay P, Soroksky A, Girault C, Han F, Hui DS, Papadakos PJ, Ambrosino N. Noninvasive mechanical ventilation in high-risk pulmonary infections: a clinical review. Eur Respir Rev. 2014;23(134):427-38. https://doi.org/10.1183/09059180.00009413.

16. Baker JG, Sovani M. Case for continuing community NIV and CPAP during the COVID-19 epidemic. Thorax. 2020;75(5):368. https://doi.org/10.1136/thoraxjnl-2020-214913.

17. Barker J, Oyefeso O, Koeckerling D, Mudalige NL, Pan D. COVID-19: community CPAP and NIV should be stopped unless medically necessary to support life. Thorax. 2020;75(5):367. https://doi.org/10.1136/thoraxjnl-2020-21489 0 .

18. Pazarlı AC, Ekiz T, İlik F. Coronavirus disease 2019 and obstructive sleep apnea syndrome. Sleep Breath. 2020. https://doi. org/10.1007/s11325-11020-02087-11320.

19. Feuth T, Saaresranta T, Karlsson A, Valtonen M, Peltola V, Rintala E, Oksi J. Is sleep apnoea a risk factor for Covid-19? Findings from a retrospective cohort study (pre-print). medRxiv and bioRxiv. 2020. 10.1101/2020.1105.1114.20098319; https:// www.medrxiv.org/content/20098310.20091101/20092020.20098 305.20098314.20098319v20098311.

20. Grote L, McNicholas WT, Hedner J, Collaborators E. Sleep apnoea management in Europe during the COVID-19 pandemic: data from the European Sleep Apnoea Database (ESADA). Eur Respir J. 2020. https://doi.org/10.1183/13993003.01323-2020.

21. Zhang XL, Xiao Y. Sleep health service in China during the COVID-19 outbreak. J Clin Sleep Med. 2020. https://doi. org/10.5664/jcsm.8472.

22. Kryger M, Thomas R. Home PAP devices in COVID-19 infected patients. J Clin Sleep Med. 2020. https://doi.org/10.5664/ jcsm. 8490 .

23. Craig S, West S. Guidance regarding coronavirus (COVID-19) and Obstructive Sleep Apnoea (OSA): for people who routinely use continuous positive airway pressure (CPAP), their families and health care workers. 2020. https://brit-thoracic.org.uk/media 
/455098/osa-alliance-cpap-covid-455019-advice-455020-45509 3-455020-v455010.pdf.

24. American Academy of Sleep Medicine (AASM). COVID-19 mitigation strategies for sleep clinics and sleep centers-REOPENING. AASM. 2020. https://aasm.org/covid-19-resources/covid -19-mitigation-strategies-sleep-clinics-labs/. Accessed 13 May 2020.

25. Bi Q, Wu Y, Mei S, Ye C, Zou X, Zhang Z, Liu X, Wei L, Truelove SA, Zhang T, Gao W, Cheng C, Tang X, Wu X, Wu Y, Sun B, Huang S, Sun Y, Zhang J, Ma T, Lessler J, Feng T. Epidemiology and transmission of COVID-19 in 391 cases and 1286 of their close contacts in Shenzhen, China: a retrospective cohort study. Lancet Infect Dis. 2020. https://doi.org/10.1016/s1473 -3099(20)30287-5.

26. McEnery T, Gough C, Costello RW. COVID-19: respiratory support outside the intensive care unit. Lancet Respir Med. 2020. https://doi.org/10.1016/S2213-2600(20)30176-4.

27. Aarrestad S, Wold M, Rasch-Halvorsen O, Indrekvam S, Fondenes O. NIV to patients in hospital with uncertain or detected Covid-19. Recommendations on practical implementation (nonpeer-review article). 2020. https://www.researchgate.net/publi cation/340285488_NIV_to_patients_in_hospital_with_uncer tain_or_detected_Covid-340285419_Recommendations_on_pract
ical_implementation_NIV_til_pasienter_innlagt_pa_sykeh us_ved_usikker_eller_pavist_Covid-340285419_-_NKH_anbef alinger.

28. Birring SS, Morgan AJ, Prudon B, McKeever TM, Lewis SA, Falconer Smith JF, Robinson RJ, Britton JR, Pavord ID. Respiratory symptoms in patients with treated hypothyroidism and inflammatory bowel disease. Thorax. 2003;58(6):533-6.

29. European Centre for Disease Prevention and Control. Infection prevention and control and preparedness for COVID-19 in healthcare settings - third update. 2020. https://www.ecdc.europa.eu/ en/publications-data/infection-prevention-and-control-and-prepa redness-covid-19-healthcare-settings.

30. Rapoport DM. CPAP, Non Invasive Ventilation (NIV) by Mask and Use of NIV systems for intubated patients in the time of Corona patient surge. 2020. https://www.thoracic.org/profession als/clinical-resources/disease-related-resources/bilevel-and-nivfor-corona-20_03_25.pdf.

Publisher's Note Springer Nature remains neutral with regard to jurisdictional claims in published maps and institutional affiliations. 